\title{
Commentary: Thrombosis and hemorrhage, yin and yang
}

\author{
Hellmuth R. Muller Moran, MD, and \\ Rakesh C. Arora, MD, PhD
}

The ancient Chinese yin and yang reflect the duality of universe; the dark yin is antithetical to the light yang, yet one cannot exist without the other. So too it is with thrombosis and hemorrhage in cardiac surgery. Maintaining a balance between these 2 opposed processes is necessary to successfully complete a cardiac operation, whereas too much of one (or not enough of the other) will inevitably lead to adverse events and outcomes. In no other patient population is this balance perhaps more delicate than in those who cannot receive blood products, such as patients who are a practicing Jehovah's Witness.

Murillo-Berlioz and colleagues ${ }^{1}$ present a case of a patient who was a Jehovah's Witness requiring erythropoietin stimulation to treat preoperative anemia. Despite being deemed a low thrombotic risk, after 8 of 10 planned doses and urgent coronary artery bypass grafting, the patient suffered significant arterial and venous thrombotic complications of a submassive pulmonary embolus with carotid and aortic arch thrombosis, which was successfully treated. The team is to be commended for their efforts in preventing what could have been a disastrous outcome.

The most recent guidelines on erythropoietin-stimulating agents in cardiac surgery were developed by the European Association for Cardio-Thoracic Surgery and the European Association of Cardiothoracic Anaesthesiology in 2017. ${ }^{2}$ These were based on 3 randomized, controlled trials using a cumulative dose of 52,000 IU starting 2 days before until

From the Division of Cardiac Surgery, Department of Surgery, Max Rady College of Medicine, University of Manitoba; and Cardiac Sciences Program, St Boniface Hospital, Winnipeg, Manitoba, Canada.

Disclosures: Dr Arora has an unrestricted grant from Pfizer Canada, Inc, and has received honoraria from Abbott Nutrition and Edwards Lifesciences for work unrelated to this manuscript. Dr Muller Moran has reported no conflicts of interest.

The Journal policy requires editors and reviewers to disclose conflicts of interest and to decline handling or reviewing manuscripts for which they may have a conflict of interest. The editors and reviewers of this article have no conflicts of interest.

Received for publication Aug 6, 2020; revisions received Aug 6, 2020; accepted for publication Aug 7, 2020; available ahead of print Aug 11, 2020.

Address for reprints: Rakesh C. Arora, MD, PhD, I. H. Asper Clinical Research Institute, CR3015 - 369 Tache Ave, Winnipeg, Manitoba R2H 2A6, Canada (E-mail: rakeshcarora@gmail.com)

JTCVS Techniques 2020;4:156-7

2666-2507

Copyright (c) 2020 The Authors. Published by Elsevier Inc. on behalf of The American Association for Thoracic Surgery. This is an open access article under the CC BY-NCND license (http://creativecommons.org/licenses/by-nc-nd/4.0/).

https://doi.org/10.1016/j.xjtc.2020.08.003

2 days after surgery, ${ }^{3}$ a single 80,000 IU dose given 2 days before surgery, ${ }^{4}$ and a single $500 \mathrm{IU} / \mathrm{kg}$ dose given 1 day before surgery. ${ }^{5}$ In all 3 trials, the administration of erythropoietin reduced transfusion requirements with no apparent increase in adverse thrombotic sequelae. As none of the trial populations were as severely anemic as the patient presented herein, the intended dose (3000 IU/kg cumulatively) and duration (10 days before and continuing until surgery) may have led to excessive thrombosis through the proposed mechanism of platelet activation. However, considering the multiple potential etiologies for thrombosis, it may be premature to attribute this solely to preoperative erythropoietin stimulation. A thorough workup including investigating for hypercoagulability, patent foramen ovale, and deep vein thrombosis at the bare minimum may clarify this diagnosis.

Evidence for erythropoietin stimulation in cardiac surgery is fragmented, including multiple agents and dosing regimens $^{6}$; however, the collective evidence suggests an association with reductions in allogeneic blood product transfusion requirements. What remains unclear is whether this comes at the expense of increased thrombotic complications. In this sense, surgeons must be mindful that attempts to prevent bleeding-related complications may inadvertently expose patients to complications of an altogether different type, namely thrombosis. Further studies will hopefully clarify the optimal agent, dose, and duration of erythropoietin stimulation in severely anemic cardiac surgery patients. As the authors 
rightly state, however, the solution may be one of moderation and using the lowest dose that is effective. Preserving the balance between thrombosis and hemorrhage, yin and yang, will allow both forces to exist in harmony and-hopefully-minimize the likelihood of thrombotic and hemorrhagic complications alike.

\section{References}

1. Murillo-Berlioz A, Guinn NR, Levy JH, Milano CA. Arterial and venous thrombosis complicating coronary artery bypass grafting after use of epoetin alfa-epbx. J Thorac Cardiovasc Surg Tech. 2020;4:154-5.

2. Pagano D, Milojevic M, Meesters MI, Benedetto U, Bolliger D, von Heymann C, et al. 2017 EACTS/EACTA Guidelines on patient blood management for adult cardiac surgery. Eur J Cardiothorac Surg. 2018;53:79-111.
3. Weltert L, D’Alessandro S, Nardella S, Girola F, Bellisario A, Maselli D et al. Preoperative very short-term, high-dose erythropoietin administration diminishes blood transfusion rate in off-pump coronary artery bypass: a randomized blind controlled study. J Thorac Cardiovasc Surg. 2010;139: $621-7$.

4. Weltert L, Rondinelli B, Bello R, Falco M, Bellisario A, Maselli D, et al. A single dose of erythropoietin reduces perioperative transfusions in cardiac surgery: results of a prospective single-blind randomized controlled trial. Transfusion. 2015;55:1644-54.

5. Yoo Y-C, Shim J-K, Kim J-C, Jo Y-Y, Lee J-H, Kwak Y-L. Effect of single recombinant human erythropoietin injection on transfusion requirements in preoperatively anemic patients undergoing valvular heart surgery. Anesthesiology. 2011; 115:929-37.

6. Kei T, Mistry N, Curley G, Pavenski K, Shehata N, Tanzini RM, et al. Efficacy and safety of erythropoietin and iron therapy to reduce red blood cell transfusion in surgical patients: a systematic review and meta-analysis. Can J Anaesth. 2019; 66:716-31. 